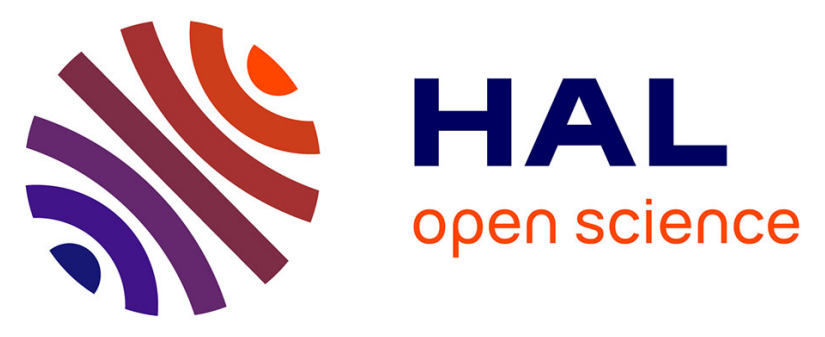

\title{
Circulating tumor DNA is prognostic and potentially predictive of eryaspase efficacy in second-line in patients with advanced pancreatic adenocarcinoma
}

Jean-Baptiste Bachet, Hélène Blons, Pascal Hammel, Iman El Hariry, Fabienne Portales, Laurent Mineur, Jean-Philippe Metges, Claire Mulot, Camille Bourreau, Jason Cain, et al.

\section{To cite this version:}

Jean-Baptiste Bachet, Hélène Blons, Pascal Hammel, Iman El Hariry, Fabienne Portales, et al.. Circulating tumor DNA is prognostic and potentially predictive of eryaspase efficacy in second-line in patients with advanced pancreatic adenocarcinoma. Clinical Cancer Research, 2020, 26 (19), pp.52085216. 10.1158/1078-0432.CCR-20-0950 . hal-02996269

\section{HAL Id: hal-02996269 \\ https://hal.sorbonne-universite.fr/hal-02996269}

Submitted on 9 Nov 2020

HAL is a multi-disciplinary open access archive for the deposit and dissemination of scientific research documents, whether they are published or not. The documents may come from teaching and research institutions in France or abroad, or from public or private research centers.
L'archive ouverte pluridisciplinaire HAL, est destinée au dépôt et à la diffusion de documents scientifiques de niveau recherche, publiés ou non, émanant des établissements d'enseignement et de recherche français ou étrangers, des laboratoires publics ou privés. 


\title{
Circulating tumor DNA is prognostic and potentially predictive of eryaspase efficacy in second-line in patients with advanced pancreatic adenocarcinoma.
}

Jean-Baptiste Bachet, ${ }^{1,2,3}$ Hélène Blons, ${ }^{3,4}$ Pascal Hammel, ${ }^{5}$ Iman El Hariry, ${ }^{6}$ Fabienne Portales, ${ }^{7}$ Laurent Mineur, ${ }^{8}$ Jean-Philippe Metges, ${ }^{9}$ Claire Mulot, ${ }^{3}, 10$ Camille Bourreau ${ }^{3,10}$, Jason Cain, ${ }^{6}$ Jérôme Cros, ${ }^{11}$ Pierre Laurent-Puig. . $^{3,4}$

\begin{abstract}
Affiliations:
${ }^{1}$ Sorbonne Université, UPMC Université, IUC, Paris France; ${ }^{2}$ Asssistance Publique - Hôpitaux de Paris Department of Hepato-gastroenterology, Groupe Hospitalier Pitié Salpêtrière, Paris, France; ${ }^{3}$ Centre de Recherche des Cordeliers, INSERM, CNRS, Sorbonne Université, USPC, Université de Paris, Equipe labellisée Ligue Nationale contre le cancer, Paris, France; ${ }^{4}$ Asssistance Publique - Hôpitaux de Paris, Department of biochemistry, Hôpital Européen Georges Pompidou, Paris, France ; ${ }^{5}$ Assistance Publique - Hôpitaux de Paris, Université de Paris, Medical Oncology Unit, Hôpital Beaujon, Clichy, France; ${ }^{6}$ ERYTECH, One Main Street, Suite 1150, Cambridge, MA 02142, USA; ${ }^{7}$ Parc Euromedecine, 208 Rue Des Apothicaires, 34070 Montpellier, France; ${ }^{8}$ Institut Sainte Catherine, Gastrointestinal and Liver Cancer Unit, Chemin de baigne pieds, Avignon, France; ${ }^{9}$ CHRU de Brest - Hôpital Morvan, 2 Avenue Foch, Brest, France; ${ }^{10}$ Biological Ressources Center Epigenetec (BB-0033-00055) Université de Paris, INSERM; ${ }^{11}$ Assistance Publique - Hôpitaux de Paris, INSERM, Paris University, Department of Pathology Hôpital Beaujon, Clichy, France.
\end{abstract}

Corresponding author: Prof Pierre Laurent-Puig,

Centre de Recherche des Cordeliers, INSERM, CNRS, Sorbonne Université, USPC, Université Paris Descartes, Université Paris Diderot, Equipe labellisée Ligue Nationale contre le cancer, Paris, France

Direct line: +33142862081

E-mail: pierre.laurent-puig@parisdescartes.fr

Running title: circulating tumor DNA and eryaspase

Conflict of interest statement: J.B. Bachet has received personal fees from Amgen, AstraZeneca, Bayer, Merck Serono, Pierre Fabre, Roche, Sanofi, Servier, Shire, and nonfinancial support from Amgen, Merck Serono, and Roche. H. Blons has received personal fees from Astra-Zeneca, Merck Serono, Amgen, Boehringer Ingelheim and Pfizer, outside the submitted work. P. Hammel has received personal fees from Amgen, AstraZeneca, Celgene, Erytech Pharma, Halozyme, Mylan, Rafael Pharmaceuticals, and Vect-Horus. I. El Hariry has the leadership of Erytech Pharma and is employed by Erytech Pharma. F. Portales has received personal fees from Sanofi. J.P. Metges has received personal fees Bristol-Myers Squibb, Lilly, Novartis, Sanofi, and Syncore. J. Cain is employed by Erytech Pharma. J. Cros has received personal fees from Novartis. P. Laurent-Puig has received grants from AGEO during the conduct of the study; personal fees from Amgen, Merck Serono, Boehringer Ingelheim, Astrazeneca, Pfizer, Bristol-Myers Squibb, outside the submitted work.

L. Mineur, C. Mulot and C. Bourreau declare no competing interests. 


\section{Statement of translational relevance}

Eryaspase is composed of L-asparaginase encapsulated in erythrocytes. It targets asparagine used by non-canonical pathways constitutively activated by KRAS signaling pathway in 80 to $90 \%$ of pancreatic cancers. In combination with chemotherapy, eryaspase was associated with a promising activity in a randomized phase 2 trial. Circulating tumor DNA (ctDNA) was assessed from plasma samples of patients included in this trial.

At baseline, ctDNA was detectable in two thirds of patients and was a strong prognostic factor. Early change of ctDNA level was significantly correlated with all oncologic outcomes.

A significant interaction was observed between the presence of ctDNA and eryaspase efficacy.

We confirm in a phase 2 trial the interest of ctDNA, at baseline and in monitoring under treatment. Moreover, presence of ctDNA could be a predictive biomarker of eryaspase efficacy and had to be assessed in the ongoing phase 3 trial. 


\section{Abstract}

\section{Background:}

Eryaspase is composed of L-asparaginase encapsulated in erythrocytes and has demonstrated significant efficacy in a randomized phase 2 trial. We assessed the prognostic and predictive value of circulating tumor DNA (ctDNA) in patients plasma included in this trial.

\section{Patients and methods:}

Samples prospectively collected pre-treatment were centrally analyzed by next-generation sequencing. Prognostic values of baseline ctDNA and ctDNA early changes between day 0 and 28 were assessed in both arms combined on objective response rate (ORR), progression free survival (PFS) and overall survival (OS); three groups were defined: negative ctDNA (Neg), ctDNA responders (Resp) and ctDNA non-responders (NResp). Predictive value of ctDNA for eryaspase efficacy was investigated.

\section{Results:}

CtDNA was positive at baseline in 77 patients out of the 113 tested patients (68\%). Detectable ctDNA was an independent negative prognostic factor for OS (4.6 vs 8.8 months; $p=0.0025$ ) and PFS (1.6 vs 3.3 months; p=0.00043). Early change in ctDNA levels was correlated with ORR $(20 \%, 26 \%, 0 \% ; \mathrm{p}<0.04)$, PFS (3.7, 3.4, 1.6 months; $\mathrm{p}<0.0001)$ and $\mathrm{OS}(11.7,6.5,4.3$ months; $\mathrm{p}<0.0001)$ according to the three defined groups (Neg, Res, NResp, respectively). In patients with ctDNA detectable at baseline, eryaspase was associated with better PFS $(\mathrm{HR}=0.53 ; 95 \% \mathrm{CI}: 0.3-0.94)$ and $\mathrm{OS}(\mathrm{HR}=0.52 ; 95 \% \mathrm{CI}: 0.29-0.91)$

\section{Conclusion:}


We confirm from a prospective randomized trial that $1 /$ the presence of ctDNA at baseline is a major prognostic factor, $2 /$ the early change of ctDNA correlates with treatment outcome and 3/ the ctDNA could be a predictive biomarker of eryaspase efficacy.

Trial registration: $\mathrm{NCT} 02195180$

Keywords: L-asparaginase, circulating tumor DNA, phase 2, prognostic, predictive 


\section{Introduction}

Pancreatic adenocarcinoma (PAC) incidence increases in many countries and is expected to become the second leading cause of cancer death in 2030 (1). Despite some progress, its prognosis remains poor with five-year survival rate of $9 \%$ all-stages combined (2). During the last 10 years, two chemotherapy regimens have demonstrated a clinical benefit in comparison to gemcitabine alone in first-line in metastatic patients: the FOLFIRINOX and the gemcitabine plus nab-paclitaxel regimen $(3,4)$. The benefit of a second-line chemotherapy has been formally demonstrated in the CONKO-003 trial (5), and the combinations of 5Fluorouracil (5-FU) plus nanoliposomal irinotecan and of 5-FU plus oxaliplatin have been validated as standard treatments after progression under a gemcitabine based first-line chemotherapy $(6,7)$.

New drugs developments are needed to improve our therapeutic possibilities and increase the overall survival of patients. One of the promising areas of research is to target some metabolites, such as glutamine or asparagine, used by non-canonical pathways constitutively activated by KRAS signaling pathway in 80 to $90 \%$ of pancreatic cancers $(8,9)$.

Eryaspase is a novel approach to deliver asparaginase that is encapsulated within erythrocytes and administered as intravenous infusion. Eryaspase is well tolerated as monotherapy (10), and in combination with chemotherapy (gemcitabine or FOLFOX) in a randomized phase $2 \mathrm{~b}$ trial (11). Significant increases of progression free survival (PFS) (HR=0.56; 95\% CI: 0.370.84; $\mathrm{p}=0.005)$, and overall survival $(\mathrm{OS})(\mathrm{HR}=0.60 ; 95 \% \mathrm{CI}: 0.41-0.87 ; \mathrm{p}=0.008)$, and a good safety profile were observed. A randomized phase 3 trial is currently ongoing (EndraCT: 2018-000572-15).

Circulating tumor DNA (ctDNA) can be applied to monitor response and resistance to systemic therapy and to capture tumor heterogeneity better than tissue biopsies (12). Its 
testing is highly specific but its sensitivity is influenced by technical issues and by tumor characteristics (12-15). In patients with PAC at diagnosis, the detection of ctDNA and the level of ctDNA if detectable are highly prognostic all stages combined $(15,16)$. Moreover, preliminary data suggests that the evolution of ctDNA under chemotherapy may be an early predictive biomarker of treatment efficacy $(15,17)$.

In this study, we investigated the prognostic and predictive value of ctDNA in the randomized phase $2 \mathrm{~b}$ trial that compared chemotherapy with or without eryaspase in second-line treatment of patients with advanced PAC. 


\section{Patients and Methods}

\section{Study design, patients and sample collection}

This multicenter, open-label, randomized phase $2 \mathrm{~b}$ trial was conducted by the GERCOR group ("Groupe coopérateur multidisciplinaire en Oncologie”) and was sponsored by Erytech Pharma (NCT02502656). All the patients gave their written informed consent. The trial was conducted in accordance with the protocol and principles of International Conference of Harmonization Good Clinical Practices and Declaration of Helsinki and was approved by an independent ethics committee. Details of this study have been previously published (11). Briefly, eligible patients were randomized in a 2:1 ratio to receive eryaspase plus chemotherapy (gemcitabine or mFOLFOX6 according to previously administered first-line) or chemotherapy alone. Tumor assessments were done every 8 weeks using RECIST 1.1 criteria.

As part of the study, plasma samples of included patients were collected at day 1 of first cycle (baseline), second cycle and third cycle.

\section{Circulating tumor DNA assessment}

ctDNA detection was performed by NGS as previously described (15). Briefly, Circulating cell-free DNA was extracted from plasma by using the Maxwell@ RSC ccfDNA Plasma Kit (Promega, France) and sequenced using the AmpliSeq Colon and Lung Cancer Panel V2 (22 genes). Samples were analyzed after BAM recalibration using a specific algorithm developed to detect allelic ratios $<2 \%$, the BPER method.

\section{Statistical analyses}


The analysis plan included the evaluation of objective response rate (ORR), PFS and OS in the intent to treat (ITT), and as a function of the treatment arm (eryaspase vs control).

The median (range) or mean (standard deviation, SD) and frequency (percentage) were used to describe continuous and categorical variables, respectively. Medians and proportions were compared using the Wilcoxon-Mann-Whitney and chi-square test, respectively, or with Fisher's exact test if appropriate. PFS and OS were estimated using the Kaplan-Meier method. As exploratory purpose univariate and multivariate Cox analyses were done to estimate hazard ratio with $95 \%$ confidence interval (CI).

For quantitative analysis of ctDNA we used variant allelic fraction (VAF). In case of several mutations identified in the same patient, the highest value was retained. The prognostic value of ctDNA was assessed by a Cox model. To draw survival curves, ctDNA value was divided in VAF tertiles.

To assess the early variation of ctDNA, we calculated a ratio between the VAF measured at day 1 of first cycle (day 1) and at day 1 of the second cycle (day 28). We used the maximal VAF (maxVAF) at day 1 of first cycle (P1); the corresponding mutation was selected and if the mutation was present in the plasma sampling at day 1 of the second cycle $(\mathrm{P} 2)$ the ratio was calculated as follow: (maxVAF_P1 $1_{\text {mutA }}-\mathrm{VAF}$ P $\left.2_{\text {mutA }}\right) / \operatorname{maxVAF} \mathrm{P} 1_{\text {mutA }}$. If the mutation corresponding to the maximal VAF at P1 was not present at $\mathrm{P} 2$ and if one or more mutations was present at $\mathrm{P} 2$, the common mutations between the 2 time points were selected and the mutation with the highest VAF at P2 was used to calculate the ratio as follow: (VAF_P1 mutAVAF_P 2 mutA $) / V A F \_P 1$ mutA (this type of calculation was used in 2 cases). If no mutation was present at $\mathrm{P} 2$ the ratio was calculated as follow: maxVAF_P1 $1_{\text {mut }} / \operatorname{maxVAF} \mathrm{P} 1_{\text {mut }}$ leading to a ratio at 1 (this type of calculation was used in 11 cases). If no mutation was present at P1 and one or more mutation was present at P2 the ratio was calculated at follow: (0maxVAF_P 2 mutA $) / V A F \_P 2$ mutA and lead to a ratio of -1 (this type of calculation was used in 
4 cases). In the cases with 2 different unique mutations present at the 2 time points, the ratio was calculated as follow VAF_P1 $1_{\text {mutA }}-\mathrm{VAF} P{ }_{2}{ }_{\text {mutB }} / V A F+P 1$ mutA (this type of calculation was used in 1 case). Based on this ratio, we defined 3 groups of patients: patients with no detectable ctDNA at P1 and P2 were classified in a "negative ctDNA" group; patients with ctDNA at least P1 or P2 were divided in 2 groups according to the ratio median value. For both arms combined, prognostic value of defined groups was assessed according to RECIST criteria (ORR and disease control rate), then on PFS and OS.

Finally, we evaluated the effect of ctDNA at baseline on efficacy of treatment by assessing an interaction between the presence of ctDNA and survival (OS and PFS) using a univariate and multivariate analyses. A significant p-value was defined as a p-value $<0.01$ at the exception of interaction analyses. A significant interaction was defined by a $p$-value $<0.05$, and an interesting interaction by a p-value $<0.1$. All statistical analyses were performed with $\mathrm{R}$ survival package. 


\section{Results}

\section{Patients' characteristics}

At least one plasma sample was available in 122 of the 141 patients (87\%). Plasma samples were available at baseline in 117 patients and at one month (day 1 of $2^{\text {nd }}$ cycle) in 88 patients. Characteristics at baseline of the 122 patients with at least one plasma sample available were not different of those of the 141 patients included in the phase IIb trial (see supplementary Data File S1). OS and PFS of the patients with or without available plasma sample were not different (see supplementary Data File S2). Similar to the results in the ITT population $(\mathrm{N}=141)$, eryaspase was associated with a significant improvement of both OS and PFS in this subgroup of 122 patients (see supplementary Data File S2).

\section{ctDNA analysis at baseline}

For baseline time point, failure of sequencing was observed in 4 patients either due to too low amount of DNA or non-interpretable sequencing. CtDNA was detectable by the presence of at least one mutated gene in 77 of 113 patients (68.1\%). Among those, the most frequent mutated genes were $\operatorname{KRAS}(\mathrm{n}=64,83 \%)$ and $\operatorname{TP} 53(\mathrm{n}=38,49 \%)$. The number of mutated genes identified was 4 in one patient (1\%), 3 in 9 patients (12\%), two in 33 patients (43\%) and one in 34 patients $(44 \%)$. The most frequent combination of mutations, KRAS and TP53, was observed in 34 patients (44\%).

No difference in baseline characteristics was observed between patients with or without detectable ctDNA (see supplementary Data File S3).

Prognostic value 
Among the 113 patients for whom NGS analysis was available at baseline, the presence of ctDNA was associated with significant shorter OS (median 4.6 vs 8.8 months; $p=0.0025$ ) and PFS (median 1.6 vs 3.3 months; $\mathrm{p}=0.00043$ ). The hazard ratio (HR) adjusted to gender, CA19.9 at baseline, treatment arm, number of metastatic site and delay before the inclusion were 1.92 (95\% CI: 1.18-3.1) and 2.13 (95\% CI: 1.3-3.5) for OS and PFS, respectively (Figure 1A and 1B). ORR was not significantly different among patients with or without detectable ctDNA: $10.4 \%(8 / 77)$ vs $13.9 \%(5 / 36)$, respectively.

The mean of the maximum of the variant allelic fraction (VAF) at baseline was 0.097 (median: 0.025; range [0-0.74]). The maximal VAF frequency observed at baseline was significantly negatively correlated with OS (HR=23.9; 95\% CI: 6.7-84.6; $\mathrm{p}<0.0001)$ and PFS $(\mathrm{HR}=8.27 ; 95 \% \mathrm{CI}: 2.4-28.3 ; \mathrm{p}=0.0008)$ in univariate analysis. In multivariate analysis, a significant correlation was observed with $\mathrm{OS}(\mathrm{HR}=16.8 ; 95 \% \mathrm{CI}: 3.83-73.58 ; \mathrm{p}=0.00018)$ and a clear trend with PFS (HR=5.66; 95\% CI: 1.43-22.39; $\mathrm{p}=0.0135)$ (see supplementary Data File S4). Prognostic value of ctDNA at baseline was then analyzed by tertiles according to VAF frequency (cut points: 0.007 and 0.0683). Characteristics of patients of three tertiles are described in supplementary Data File S5. Higher tertiles of VAF frequency was prognostic of OS and PFS (Figure 2A and 2B).

\section{Quantitative monitoring of ctDNA under treatment}

The mean of the VAF ratio between P1 and P2 was 0.12 (IQR: 1.06) and the median 0.28 (range [-5.33-1]). Twenty-five patients were classified in the "negative ctDNA" group (no ctDNA at P1 and P2); 23 in the "ctDNA responders" group and 23 in the "ctDNA nonresponders" group.

ORR was correlated with the groups defined by ctDNA variation: $20 \%(5 / 25), 26 \%(6 / 23)$ and $0 \%(0 / 23)$ in "negative ctDNA", "ctDNA responders" and "ctDNA non-responders" 
groups $(\mathrm{p}<0.04)$, respectively. Significant correlation was observed for disease control rate: $68 \%(\mathrm{n}=17 / 25), 61 \%(14 / 23)$ and 22\% (5/23) in "negative ctDNA", "ctDNA responders" and “ctDNA non-responders" groups $(\mathrm{p}=0.002)$, respectively.

For both arms combined, the groups defined by ctDNA variation were significantly correlated with OS and PFS (Figure 3A and 3B).

Plasma samples were available before the first day of the three cycles in 40 patients. Patients who had a disease control had more frequently a negative ctDNA or a decrease of the maximal VAF after treatment initiation (supplementary Data File S6).

\section{ctDNA and treatment arm}

For OS, an interesting interaction between the presence of ctDNA at baseline and eryaspase efficacy was observed in univariate $(\mathrm{HR}=0.39 ; 95 \% \mathrm{CI}: 0.14-1.09 ; \mathrm{p}=0.073)$ and multivariate $(\mathrm{HR}=0.35 ; 95 \% \mathrm{CI}: 0.12-1.05 ; \mathrm{p}=0.060)$ analyses. For PFS, there was a trend for an interesting interaction in univariate analysis $(\mathrm{HR}=0.47 ; 95 \% \mathrm{CI}: 0.18-1.22 ; \mathrm{p}=0.122)$ and in multivariate $(\mathrm{HR}=0.42 ; 95 \% \mathrm{CI}: 0.15-1.20 ; \mathrm{p}=0.105)$ analysis (see supplementary Data File S7).

Among patients with detectable ctDNA at baseline, eryaspase was associated with a not significant increase in disease control rate $(47 \%(n=15 / 32)$ vs $29 \%(n=4 / 14) ; p=0.3)$ and a significant increase of OS $(\mathrm{HR}=0.52 ; 95 \% \mathrm{CI}: 0.29-0.91: \mathrm{p}<0.001)$ and $\mathrm{PFS}(\mathrm{HR}=0.53 ; 95 \%$ CI: $0.3-0.94 ; \mathrm{p}<0.001)$. No significant difference of treatment efficacy was observed in the subgroup of patients with unknown ctDNA status (Figure 4A and 4B).

No correlation was observed between asparagine synthetase (ASNS) expression level and ctDNA status. Among patients with negative and positive ctDNA at baseline, null-low (0-1) ASNS expression rates were $72 \%(\mathrm{n}=26 / 36)$ and $68 \%(\mathrm{n}=52 / 77)(\mathrm{p}=0.776)$, respectively. 


\section{Discussion}

The aim of this exploratory translational study was to evaluate the prognostic and predictive value of ctDNA from plasma samples collected during the randomized phase 2 trial which has assessed eryaspase efficacy in second-line in patients with advanced PAC. For this, we used a NGS method adapted to plasma analysis and allowing to search the main mutated genes in PAC (15). The prognostic value of ctDNA at diagnosis (baseline) is now well established in several cancer types, and more specifically in PAC, irrespective of the stage of the disease $(13-16,18)$. The rate of detectable ctDNA at diagnosis accounts for approximately two thirds of patients with metastatic disease $(15,17-20)$. The current study represents the largest cohort investigating the prognostic and predictive value of quantitative ctDNA in second-line setting. The prevalence rate of $68 \%$ is similar to that found in other studies of metastatic PAC. To our knowledge, the features of metastatic PAC patients with undetectable ctDNA are not well described, unlike metastatic colorectal cancer for which metastatic spread to the liver is clearly correlated to detectable ctDNA (21). The detection of ctDNA seems correlated with differentiation grade and CA 19-9 level but not clearly with tumor burden (15). Given the strong prognostic value of ctDNA at baseline, future studies should aim to better define the subset of patients with undetectable ctDNA, with the goal of stratifying future trials based on ctDNA content.

In addition to its prognostic value at diagnosis, the value of the dynamic change of ctDNA during follow-up is very promising (12-14). Indeed, the effect of chemotherapy on ctDNA levels could inform on treatment efficacy $(15,20)$. In a prospective cohort of patients with advanced PAC, a significant correlation between the kinetics of ctDNA, from day 0 to day 14 , and objective response rate was reported (17). Moreover, an increase in ctDNA level under treatment indicated progression with a sensitivity of $83 \%$ and specificity of $100 \%$. Changes in 
ctDNA levels appeared more informative than changes in more "classical" biomarkers such as CA 19-9 and CEA (17). In our study, we assessed the value of early changes, between days 0 and 28 , in ctDNA levels and identified three distinct groups that were strongly correlated with ORR, PFS and OS. Generally, only half of PAC patients are able to receive second line therapy $(3,4,7)$, therefore, it is prudent to argue that identifying early disease progression based on increasing levels of ctDNA and subsequently instating salvage therapy before objective disease progression may have a positive effect on OS and improving the patients outcome.

The main strengths of this exploratory study are that approximately $85 \%$ of the patients in this trial had analyzable ctDNA samples, confirming the utility of our approach and the correlation with efficacy indicators in the ITT population. While our results are promising, there are still several outstanding issues that should be addressed in a prospective clinical trial, such as the optimal timing for collecting ctDNA samples, the ctDNA threshold and the different methods available to evaluate ctDNA. Furthermore, the clinical utility of using early evolution of ctDNA during treatment follow-up should also be addressed in future trials.

The eryaspase benefit appeared most significant for OS and PFS in the subgroup of patients with detectable ctDNA, which is also the subgroup of patients with the worst prognosis. This result could be explained either by an efficacy of eryaspase on circulating tumor cells (potentially correlated to ctDNA), or by an increase anticancer drug delivery in the subgroup of pancreatic adenocarcinomas with ctDNA positivity. Given this correlation, these results provide further support for the role of targeting metabolic pathways as a novel therapeutic modality in PAC. Interestingly, to our knowledge no specific therapy has demonstrated efficacy in a subgroup defined by the presence of ctDNA. PAC is characterized by extensive reprogramming of cellular metabolism, specifically a robust glycolytic activity and glutamine addiction (21), which plays a role in controlling proliferation of cancer cells and enabling 
invasion and metastasis in a nutrient-poor, hypoxic microenvironment. These metabolic switches are driven by the acquisition of activating KRAS mutations (22). Therefore, eryaspase provides a novel therapeutic target for the treatment of PAC $(10,11)$. The current results provide a rationale for utilizing ctDNA as a potential marker of response. At the opposite, no benefit of eryaspase was observed in the subgroup of patients with undetectable ctDNA at baseline. This observation could be due to the small number of patients of this subgroup ( $\mathrm{n}=36 ; 8$ vs 28 ). It is therefore important to confirm these findings in the ongoing phase 3 trial. ASNS expression was not predictive of eryaspase efficacy in the phase 2 trial, and no correlation was found between ASNS expression and ctDNA status.

In conclusion, we confirm that the presence of ctDNA at baseline is a prognostic factor in patients with advanced PAC. The feasibility of this approach and its potential prognostic value provides a rationale for stratifying patients in future clinical trials. Our results suggest that presence of ctDNA could be a predictive biomarker of eryaspase efficacy. Taken together, the detection of ctDNA in approximately two thirds of patients with metastatic PAC and eryaspase being associated with a good safety profile, argue for future first-line development of this combination in the event of a positive phase 3 results. 


\section{Acknowledgements}

The authors would like to thank all patients and their families participating in the trial and the SIRIC CARPEM for facilitating the access to the sequencing platform.

\section{Funding}

This work was funded by ERYTECH Pharma. The funding source was involved in the design, interpretation or conduct of this evaluation, manuscript writing, and the decision to submit or publish the data. However, the authors are fully responsible for the content of this manuscript, and the views and opinions described in the publication reflect solely those of the authors.

\section{Authors' Contributions}

Conception and design: J.B. Bachet, I. El Hariry, J. Cain, J. Cros, P. Laurent-Puig

Development and methodology: J.B. Bachet, H. Blons, I. El Hariry, J. Cain, J. Cros, P. Laurent-Puig.

Acquisition of data (provided animals, acquired and managed patients, provided facilities, etc..): J. B. Bachet, H. Blons, P. Hammel, I. El Hariry, F. Portales, L. Mineur,8 J. P. Metges, C. Mulot, C. Bourreau, J. Cain, J. Cros, P. Laurent-Puig.

Analysis and interpretation of data (e.g., statistical analysis, biostatistics, computational analysis): J.B. Bachet, H. Blons, P. Laurent-Puig.

Writing, review, and/or revision of the manuscript: J. B. Bachet, H. Blons, P. Hammel, I. El Hariry, F. Portales, L. Mineur, J. P. Metges, C. Mulot, C. Bourreau, J. Cain, J. Cros, P. Laurent-Puig.

Administrative, technical, or material support (i.e., reporting or organizing data, constructing databases): J. B. Bachet, H. Blons, C. Mulot, C. Bourreau, J. Cain, P. Laurent-Puig. Study supervision: J. B. Bachet, P. Laurent-Puig. 


\section{References}

1. Rahib L, Smith BD, Aizenberg R, Rosenzweig AB, Fleshman JM, Matrisian LM. Projecting Cancer Incidence and Deaths to 2030: The Unexpected Burden of Thyroid, Liver, and Pancreas Cancers in the United States. Cancer Research 2014;74:2913-21.

2. Siegel RL, Miller KD, Jemal A. Cancer statistics, 2019. CA A Cancer J Clin 2019;69:7-34.

3. Thierry C, Françoise D, Marc Y, Olivier B, Rosine G, Yves B, et al. FOLFIRINOX versus Gemcitabine for Metastatic Pancreatic Cancer. N Engl J Med 2011;364:1817-25.

4. Von Hoff DD, Ervin T, Arena FP, Chiorean EG, Infante J, Moore M, et al. Increased Survival in Pancreatic Cancer with nab-Paclitaxel plus Gemcitabine. N Engl J Med 2013;369:1691-703.

5. Pelzer U, Schwaner I, Stieler J, Adler M, Seraphin J, Dörken B, et al. Best supportive care (BSC) versus oxaliplatin, folinic acid and 5-fluorouracil (OFF) plus BSC in patients for second-line advanced pancreatic cancer: a phase III-study from the German CONKO-study group. Eur J Cancer 2011;47:1676-81.

6. Wang-Gillam A, Li CP, Bodoky G, Dean A, Shan YS, Jameson G, et al.; NAPOLI-1 Study Group. Nanoliposomal irinotecan with fluorouracil and folinic acid in metastatic pancreatic cancer after previous gemcitabine-based therapy (NAPOLI-1): a global, randomised, openlabel, phase 3 trial. Lancet 2016;387:545-57.

7. Ducreux M, Cuhna AS, Caramella C, Hollebecque A, Burtin P, Goéré D, et al. ESMO Clinical Practice Guidelines for diagnosis, treatment and follow-up. Ann Oncol 2015;26 Suppl 5:v56-68.

8. Son J, Lyssiotis CA, Ying H, Wang X, Hua S, Ligorio M, et al. Glutamine supports pancreatic cancer growth through a KRAS-regulated metabolic pathway. Nature 2013;496:101-5. 
9. Kawada K, Toda K, Sakai Y. Targeting metabolic reprogramming in KRAS-driven cancers. Int J Clin Oncol 2017;22:651-9.

10. Bachet JB, Gay F, Maréchal R, Galais MP, Adenis A, MsC DS, et al. Asparagine Synthetase Expression and Phase I Study With L-Asparaginase Encapsulated in Red Blood Cells in Patients With Pancreatic Adenocarcinoma. Pancreas 2015;44:1141-7.

11. Hammel P, Portales F, Mineur L, Metges JP, Andre T, De La Fouchardiere C, et al. Erythrocyte-encapsulated asparaginase (eryaspase) combined with chemotherapy in secondline treatment of advanced pancreatic cancer: an open-label, randomized Phase IIb trial. Eur J Cancer 2019;124:91-101.

12. Siravegna G, Mussolin B, Venesio T, Marsoni S, Seoane J, Dive C, et al. How liquid biopsies can change clinical practice in oncology. Ann Oncol 2019;30:1580-90.

13. Bettegowda C, Sausen M, Leary RJ, Kinde I, Wang Y, Agrawal N, et al. Detection of Circulating Tumor DNA in Early- and Late-Stage Human Malignancies. Sci Transl Med $2014 ; 6: 224 \mathrm{ra} 24$.

14. Wan JCM, Massie C, Garcia-Corbacho J, Mouliere F, Brenton JD, Caldas C, et al. Liquid biopsies come of age: towards implementation of circulating tumour DNA. Nat Rev Cancer 2017;17:223-38.

15. Pietrasz D, Pécuchet N, Garlan F, Didelot A, Dubreuil O, Doat S, et al. Plasma Circulating Tumor DNA in Pancreatic Cancer Patients Is a Prognostic Marker. Clin Cancer Res 2017;23:116-23.

16. Lee JS, Rhee TM, Pietrasz D, Bachet JB, Laurent-Puig P, Kong SY, et al. Circulating tumor DNA as a prognostic indicator in resectable pancreatic ductal adenocarcinoma: A systematic review and meta-analysis. Sci Rep 2019;9:16971.

17. Kruger S, Heinemann V, Ross C, Diehl F, Nagel D, Ormanns S, et al. Repeated mutKRAS ctDNA measurements represent a novel and promising tool for early response 
prediction and therapy monitoring in advanced pancreatic cancer. Ann Oncol 2018;29:234855.

18. Buscail E, Alix-Panabières C, Quincy P, Cauvin T, Chauvet A, Degrandi O, et al. High Clinical Value of Liquid Biopsy to Detect Circulating Tumor Cells and Tumor Exosomes in Pancreatic Ductal Adenocarcinoma Patients Eligible for Up-Front Surgery. Cancers (Basel) 2019;11(11).

19. Pietrasz D, Wang-Renault S, Dahan L, Taieb J, Le Malicot K, Rinaldi Y, et al. Methylated circulating tumor DNA (Met-DNA) as an independent prognostic factor in metastatic pancreatic adenocarcinoma (mPAC) patients. J Clin Oncol 2019;37(no. 15_suppl):4136.

20. Takai E, Totoki Y, Nakamura H, Kato M, Shibata T, Yachida S. Clinical utility of circulating tumor DNA for molecular assessment in pancreatic cancer. Sci Rep 2015;5: 18425.

21. Jones S, Zhang X, Parsons DW, Lin JC, Leary RJ, Angenendt P, et al. Core signaling pathways in human pancreatic cancers revealed by global genomic analyses. Science 2008;321:1801-6.

22. Seo JW, Choi J, Lee SY, Sung S, Yoo HJ, Kang MJ, et al. Autophagy is required for PDAC glutamine metabolism. Sci Rep 2016;6:37594. 


\section{Figure legends}

Figure 1A. Overall survival curves according to the presence or absence of ctDNA at baseline.

Forest Plot of the ctDNA presence effect on overall survival with Hazard Ratio (95\% Confidence Interval) adjusted on Age, Gender, CA19.9 levels at baseline, Treatment Arm, Number of metastatic sites, delay before inclusion.

Figure 1B. Progression free survival curves according to the presence or absence of ctDNA at baseline.

Forest Plot of the ctDNA presence effect on progression free survival with Hazard Ratio (95\% Confidence Interval) adjusted on Age, Gender, CA19.9 levels at baseline, Treatment Arm, Number of metastatic sites, delay before inclusion.

Figure 2A. Overall survival curves according to the tertiles defined by the VAF frequency of ctDNA.

Forest Plot of the ctDNA level tertiles effect on overall survival with Hazard Ratio (95\% Confidence Interval) adjusted on Age, Gender, CA19.9 levels at baseline, Treatment Arm, Number of metastatic sites, delay before inclusion.

Figure 2B. Progression free survival curves according to the tertiles defined by the VAF frequency of ctDNA.

Forest Plot of the ctDNA level tertiles effect on progression free survival with Hazard Ratio (95\% Confidence Interval) adjusted on Age, Gender, CA19.9 levels at baseline, Treatment Arm, Number of metastatic sites, delay before inclusion. 
Figure 3A. Overall survival according to the groups defined by ctDNA variation between first and second cycle.

Forest Plot of the ctDNA variation effect on overall survival with Hazard Ratio (95\% Confidence Interval) adjusted on Age, Gender, CA19.9 levels at baseline, Treatment Arm, Number of metastatic sites, delay before inclusion.

Figure 3B. Progression free survival according to the groups defined by ctDNA variation between first and second cycle.

Forest Plot of the ctDNA variation effect on progression free survival with Hazard Ratio (95\% Confidence Interval) adjusted on Age, Gender, CA19.9 levels at baseline, Treatment Arm, Number of metastatic sites, delay before inclusion.

Figure 4A. Overall survival curves according to ctDNA at baseline and treatment arm. Hazard ratio adjusted on age, gender, Ca 19-9 at baseline (elevated vs normal), treatment arm, number of metastatic site and delay before inclusion.

Figure 4B. Progression free survival curves according to ctDNA at baseline and treatment arm.

Hazard ratio adjusted on age, gender, Ca 19-9 at baseline (elevated vs normal), treatment arm, number of metastatic site and delay before inclusion. 


\section{Figure 1B}
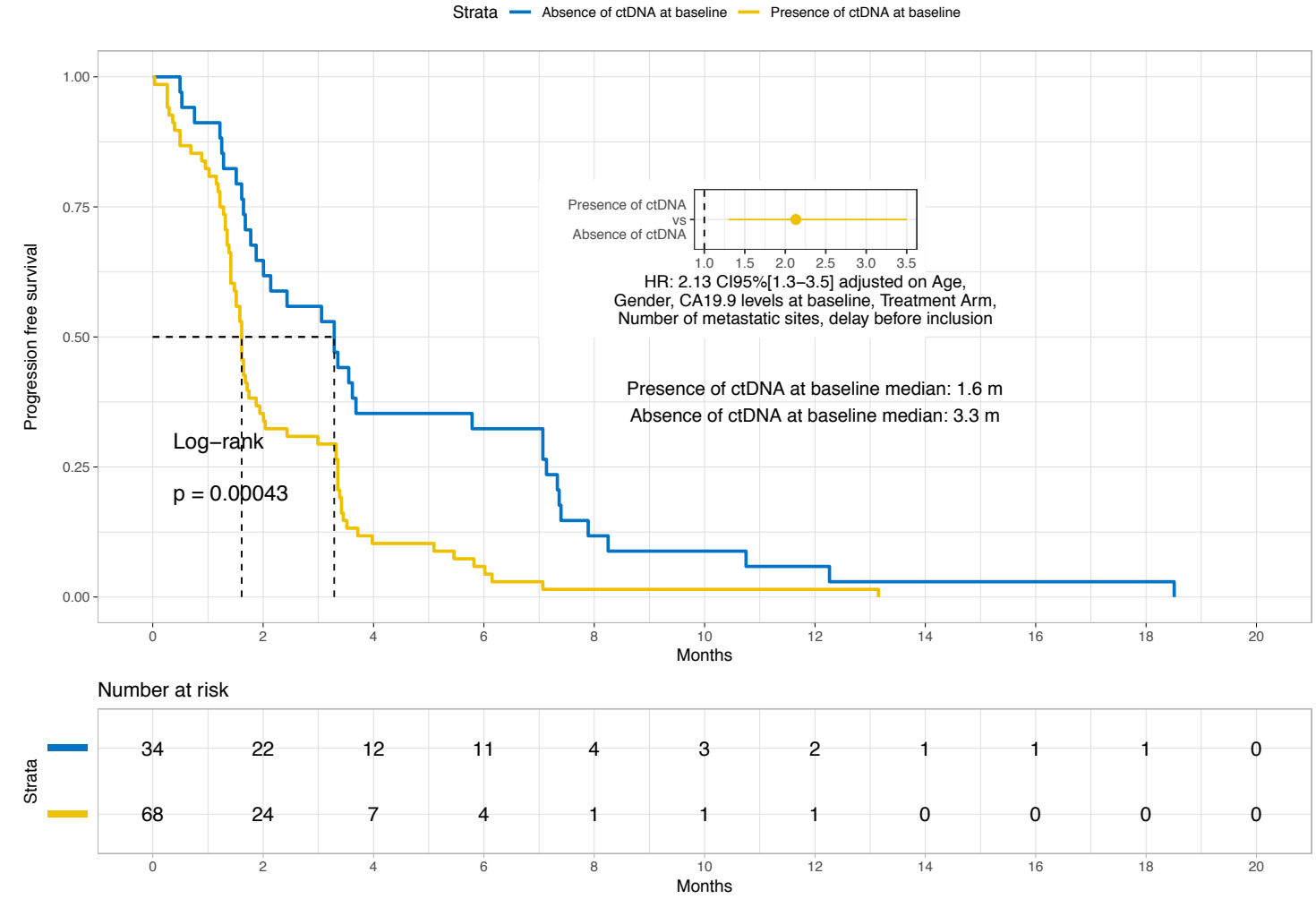
Figure 2A

Strata + oDDNA 1st tertile - atDNA 2nd tertile + aDNA 3rd tertile

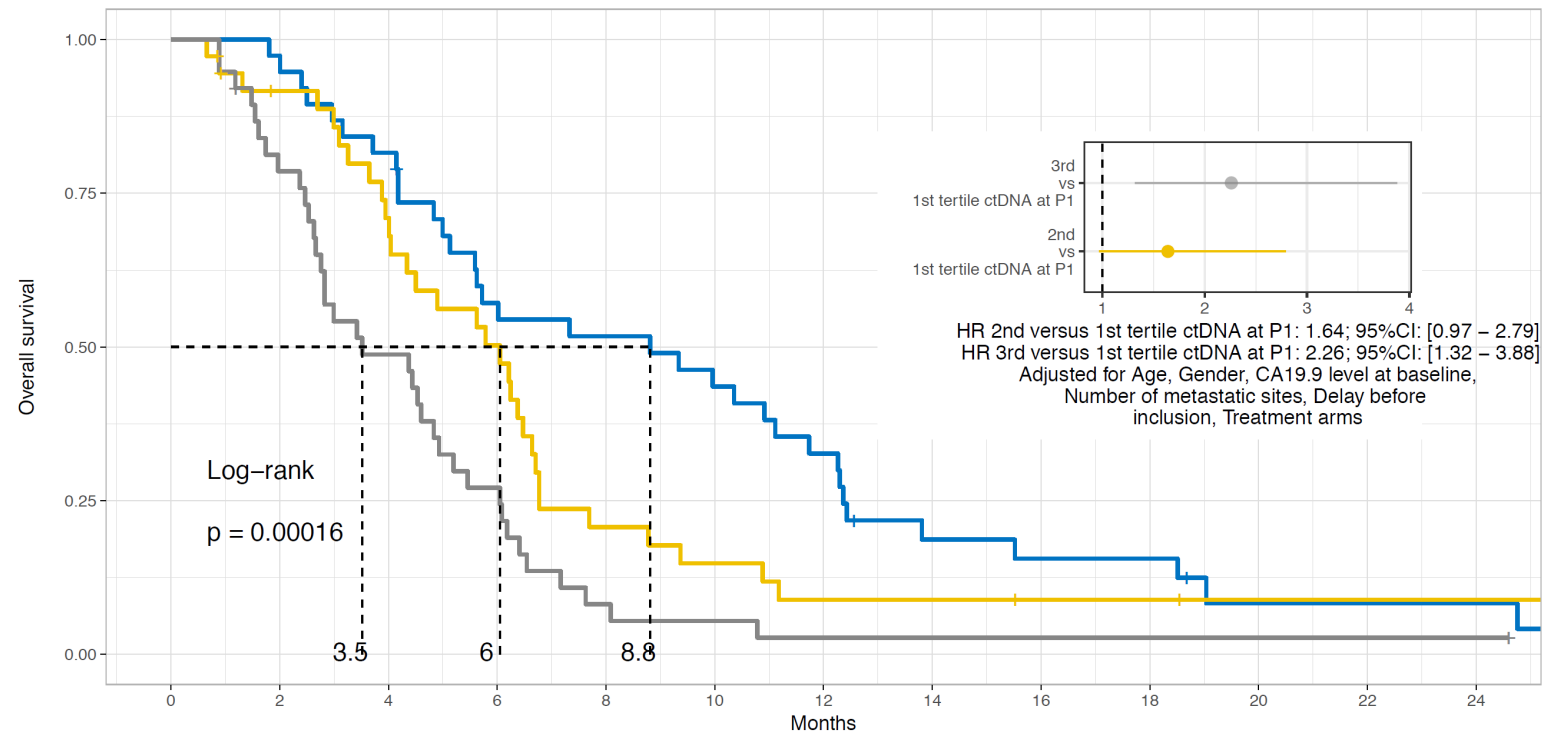

Number at risk

\begin{tabular}{|c|c|c|c|c|c|c|c|c|c|c|c|c|}
\hline - & 37 & 31 & 21 & 19 & 16 & 12 & 6 & 5 & 5 & 2 & 2 & 2 \\
\hline$=$ & 31 & 24 & 17 & 7 & 5 & 3 & 3 & 2 & 2 & 1 & 1 & 1 \\
\hline 38 & 29 & 18 & 10 & 3 & 2 & 1 & 1 & 1 & 1 & 1 & 1 & 1 \\
\hline 0 & 2 & 4 & 6 & 8 & 10 & 12 & 14 & 16 & 18 & 20 & 22 & 24 \\
\hline
\end{tabular}




\section{Figure 2B}

Strata - ctDNA 1st tertile - ctDNA 2nd tertile - ctDNA 3rd tertile
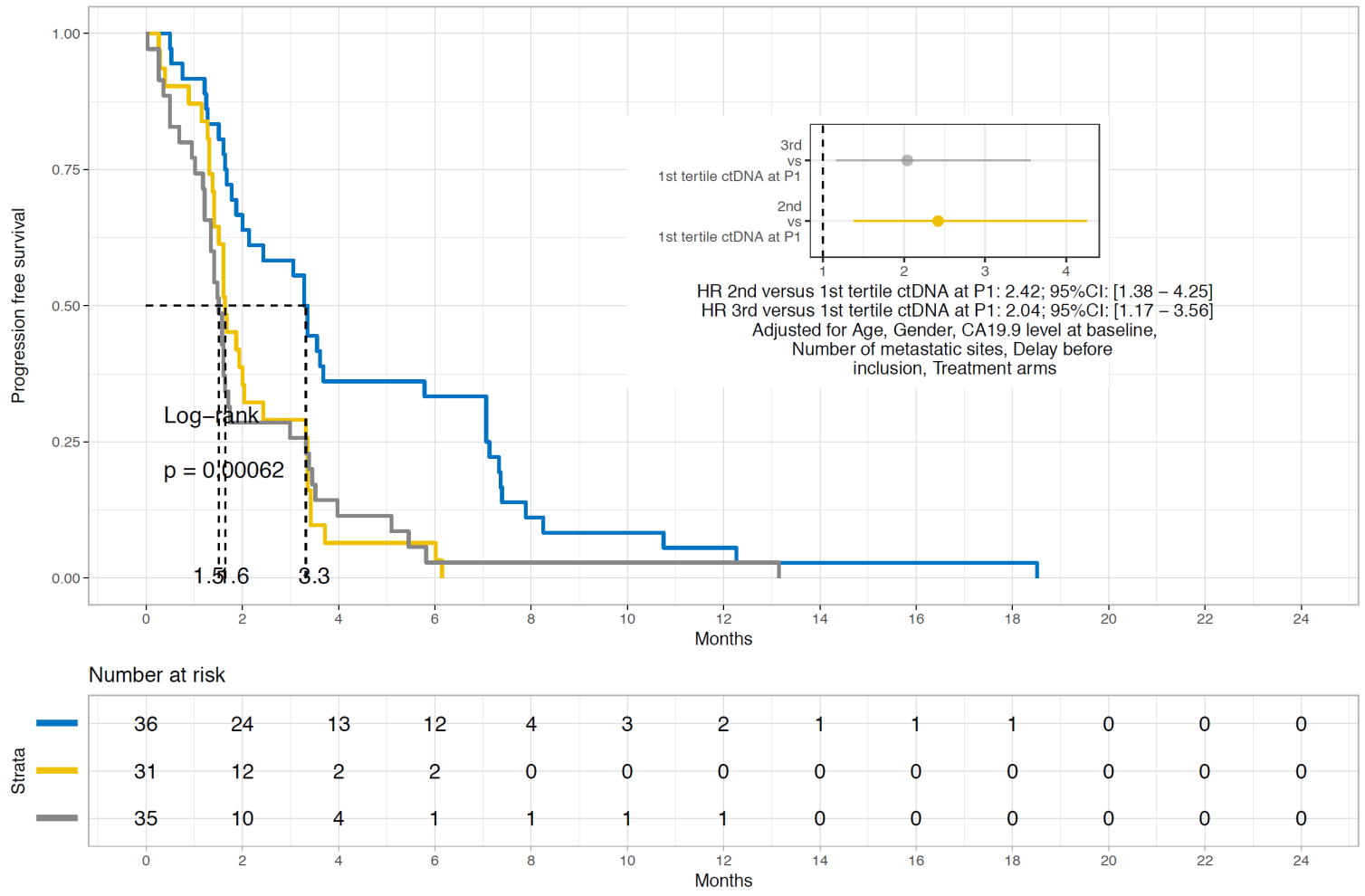
Figure 3

A/

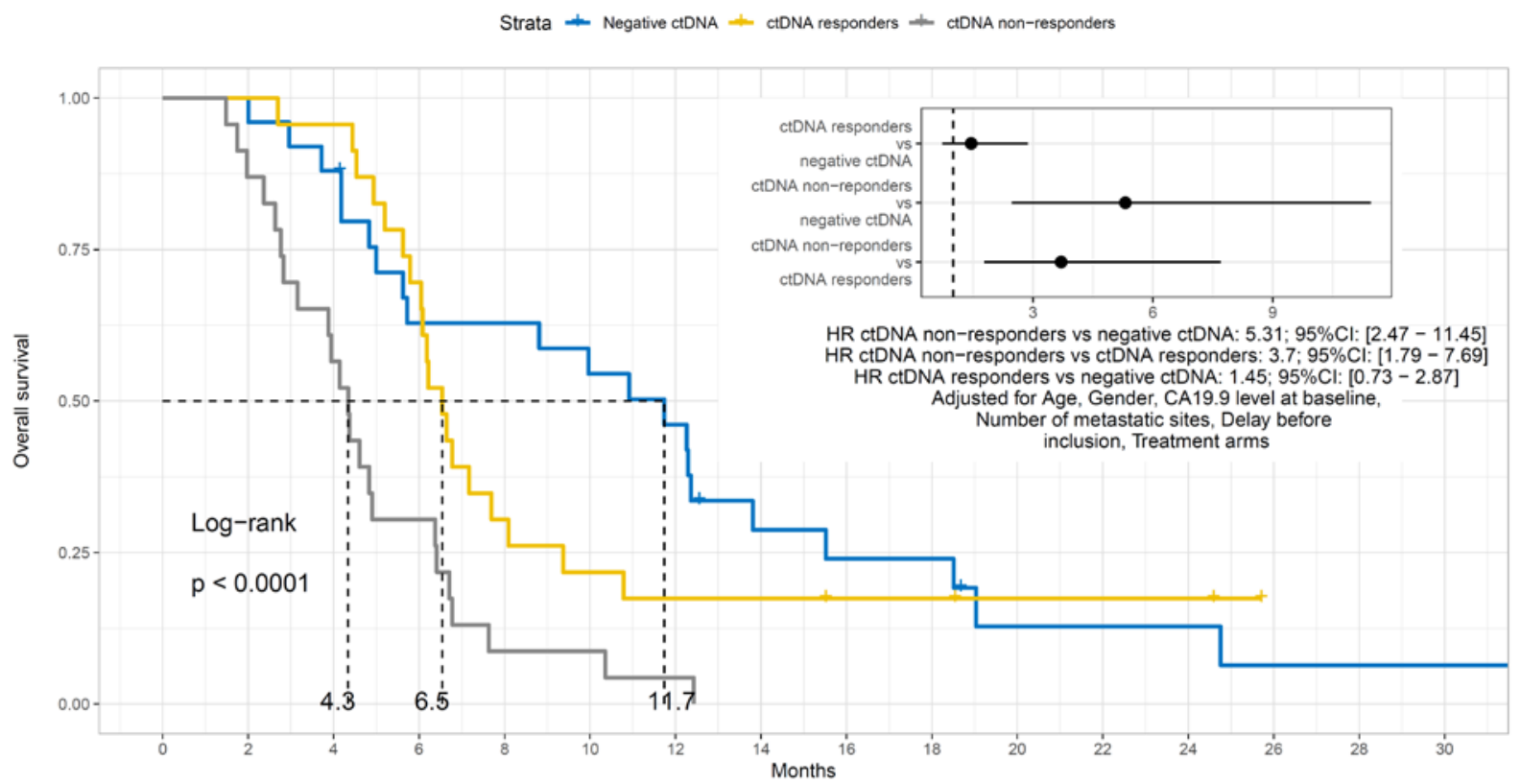

\begin{tabular}{|c|c|c|c|c|c|c|c|c|c|c|c|c|c|c|c|c|}
\hline \multicolumn{17}{|c|}{ Number at risk } \\
\hline \multirow{4}{*}{ - } & 25 & 25 & 22 & 15 & 15 & 13 & 11 & 6 & 5 & 5 & 2 & 2 & 2 & 1 & 1 & 1 \\
\hline & 23 & 23 & 22 & 16 & 7 & 5 & 4 & 4 & 3 & 3 & 2 & 2 & 2 & 0 & 0 & 0 \\
\hline & 23 & 20 & 13 & 7 & 2 & 2 & 1 & 0 & 0 & 0 & 0 & 0 & 0 & 0 & 0 & 0 \\
\hline & 0 & 2 & 4 & 6 & 8 & 10 & 12 & 14 & 16 & 18 & 20 & 22 & 24 & 26 & 28 & 30 \\
\hline
\end{tabular}

B/ 


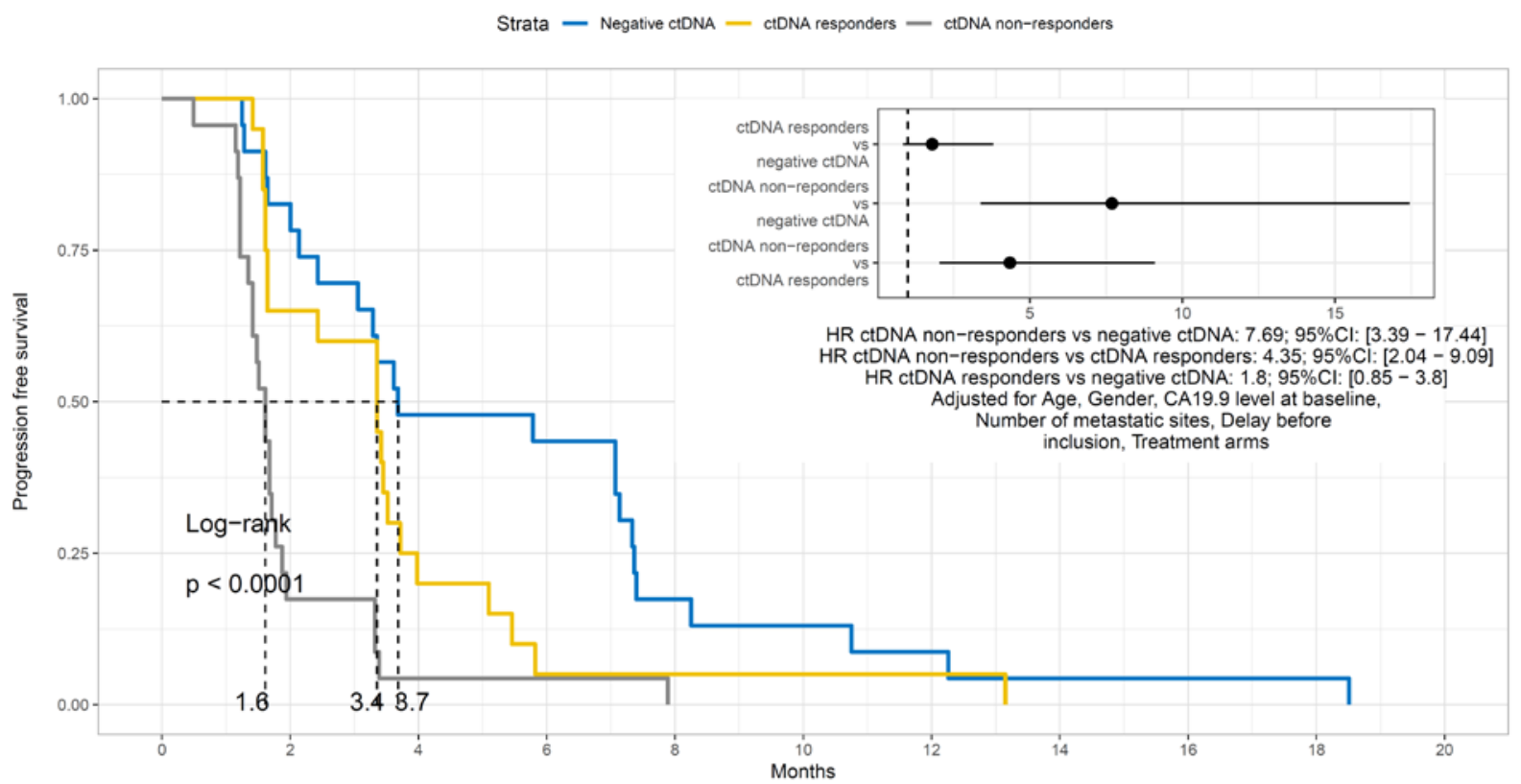

\begin{tabular}{|c|c|c|c|c|c|c|c|c|c|c|c|}
\hline \multirow{2}{*}{$\begin{array}{r}1 \\
-\end{array}$} & \multicolumn{11}{|c|}{ Number at risk } \\
\hline & 23 & 19 & 11 & 10 & 4 & 3 & 2 & 1 & 1 & 1 & 0 \\
\hline \multirow{3}{*}{ 营 } & 20 & 13 & 4 & 1 & 1 & 1 & 1 & 0 & 0 & 0 & 0 \\
\hline & 23 & 4 & 1 & 1 & 0 & 0 & 0 & 0 & 0 & 0 & 0 \\
\hline & 0 & 2 & 4 & 6 & 8 & $\begin{array}{c}10 \\
\text { Montt }\end{array}$ & 12 & 14 & 16 & 18 & 20 \\
\hline
\end{tabular}


Figure 3A

Strata - Negative ctDNA - cIDNA responders - CtDNA non-responders
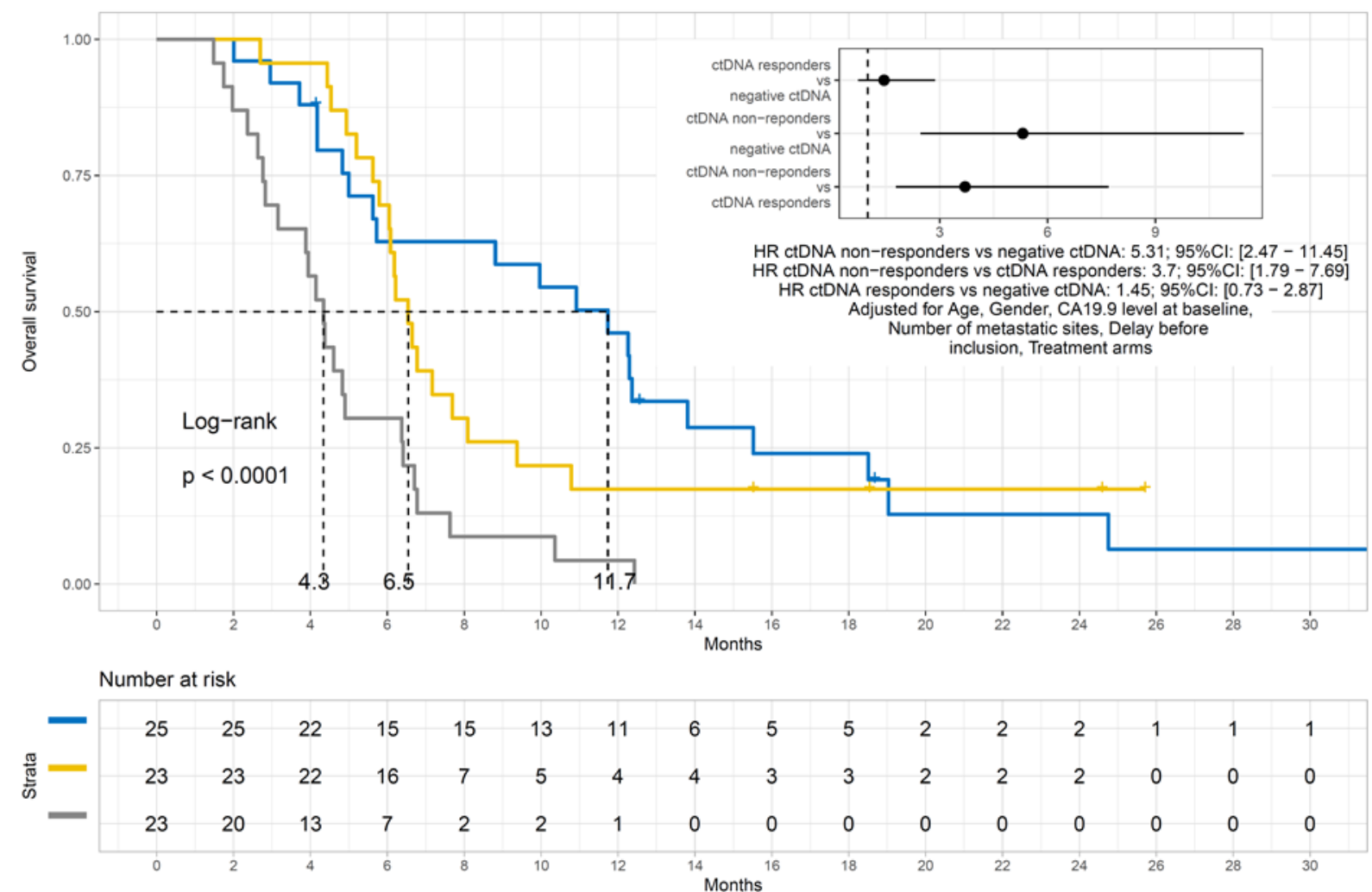


\section{Figure 3B}

Strata - Negative ctDNA - CtDNA responders - CtDNA non-responders

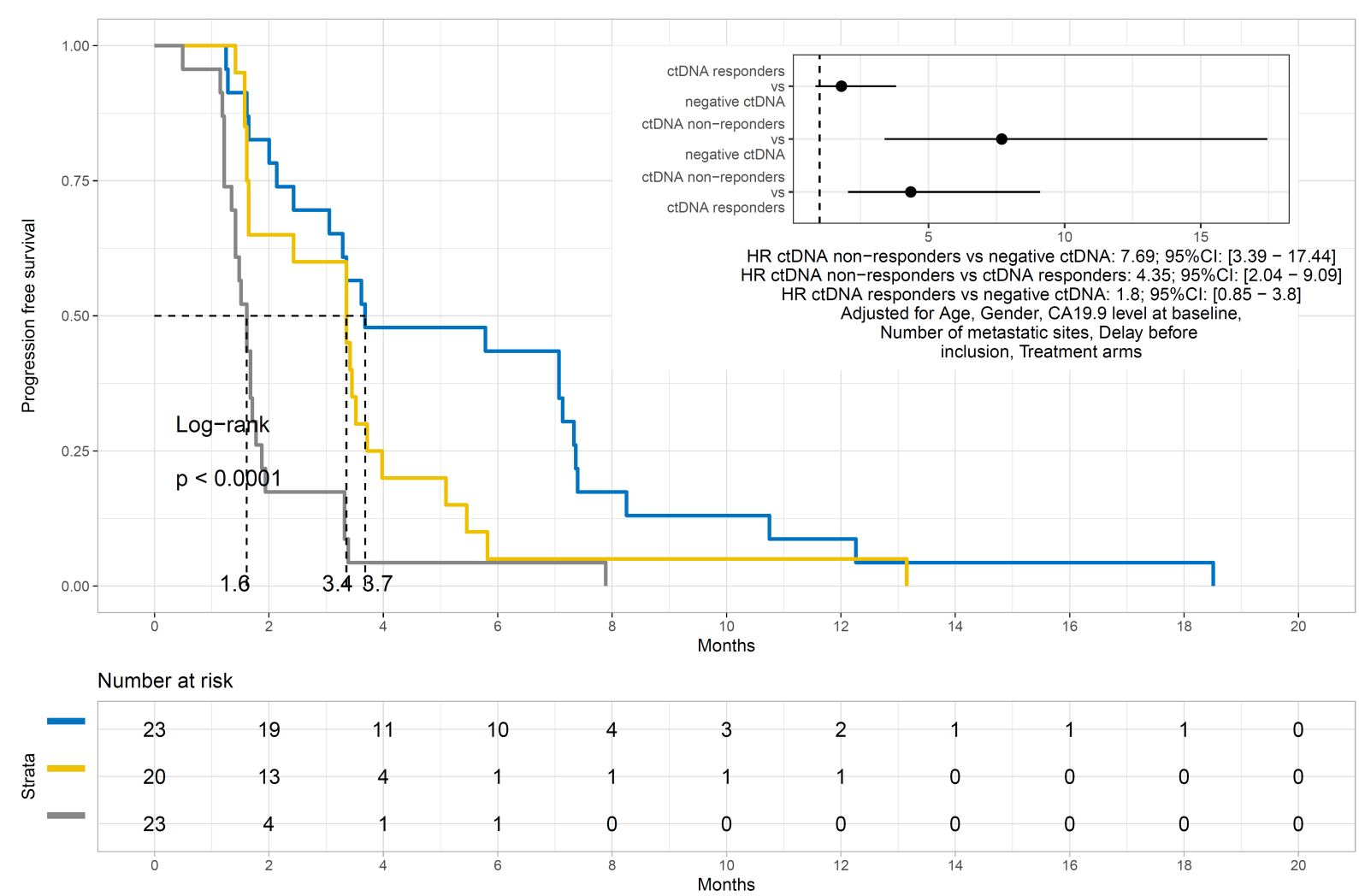


Figure 4A

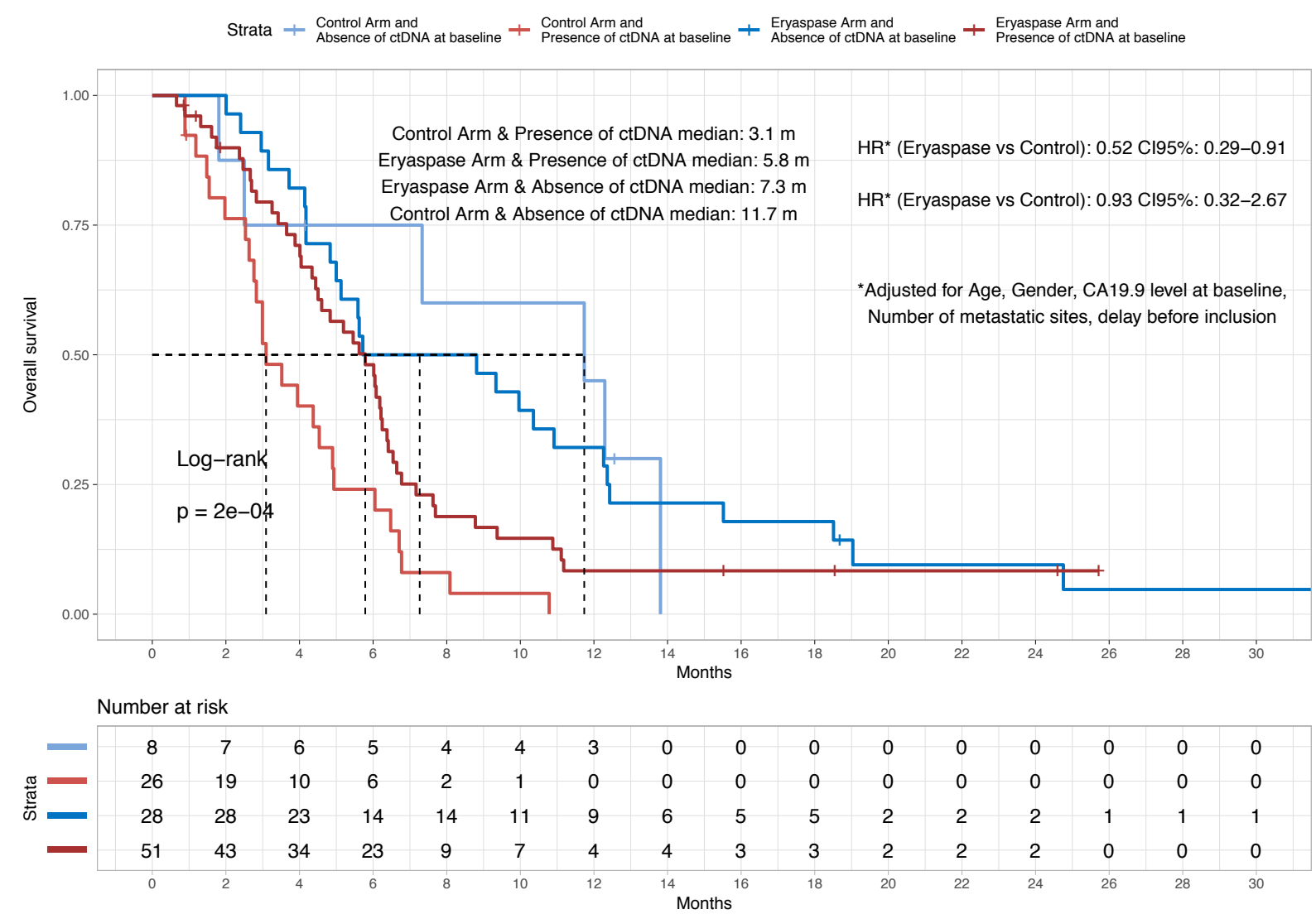


Figure 4B

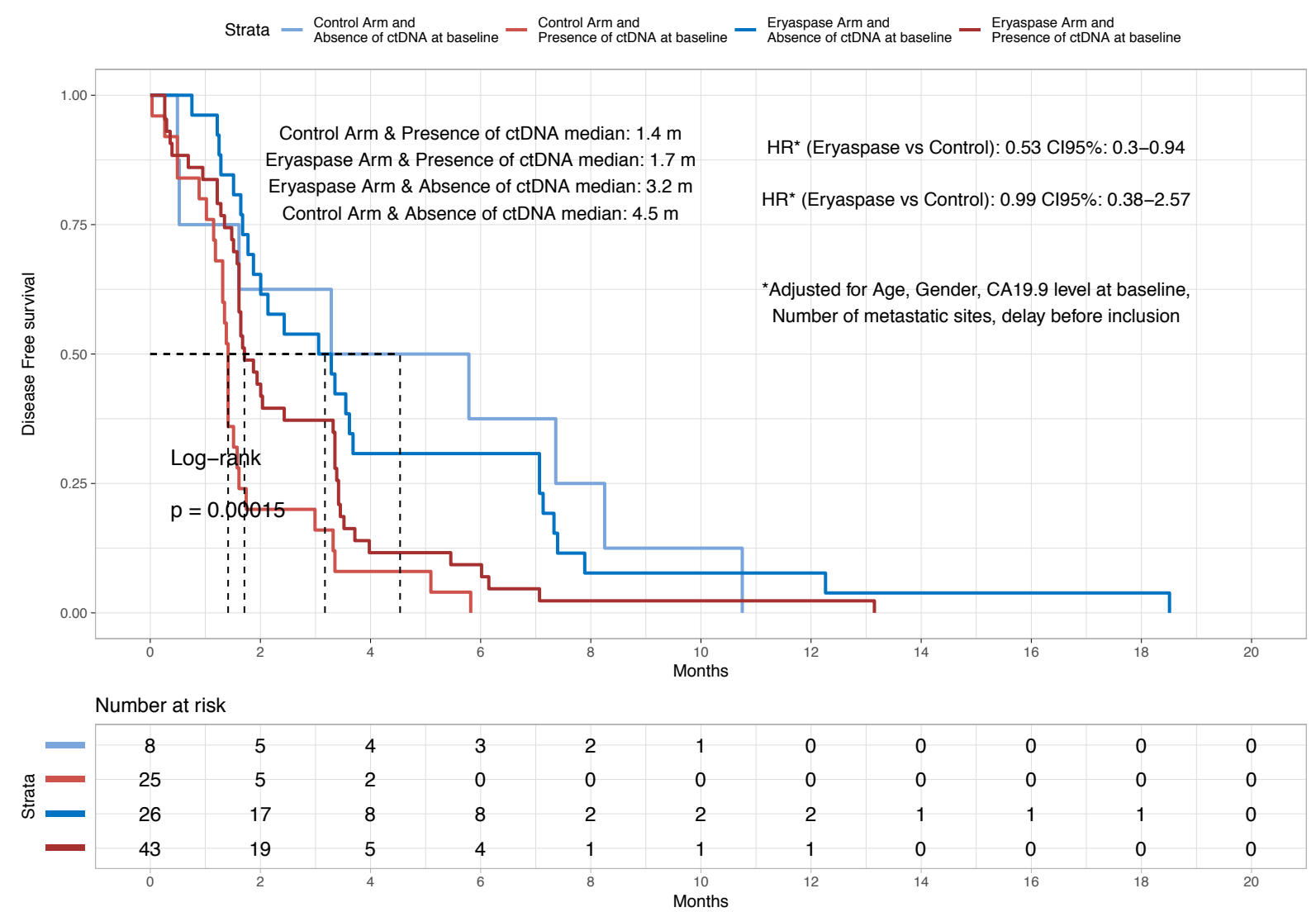


Supplementary Data File S1: Description of the studied population

Patients included in translational study

$(n=122)$

Age

Mean (SD)

Median [Min, Max]

\section{Gender}

F

M

Treatment Arm intent to treat

Control arm

Eryaspase arm

CA19.9 Normal vs Elevated

Normal

Elevated

Missing

Time from initial diagnosis to randomization

Mean (SD)

Median [Min, Max]

Number of metastatic sites

Mean (SD)

Median [Min, Max]

Number of metastatic sites

$$
1 \text { or } 2 \text { sites }
$$

more than 2 sites

$$
62.4(9.48)
$$

$63.0[37.0,84.0]$

$62.6(9.72)$

$63.0[37.0,84.0]$

$\begin{array}{ll}52(42.6 \%) & 58(41.1 \%) \\ 70(57.4 \%) & 83(58.9 \%)\end{array}$

$36(29.5 \%)$

$46(32.6 \%)$

$86(70.5 \%)$

$95(67.4 \%)$

$22(18.0 \%)$

$25(17.7 \%)$

$88(72.1 \%)$

$97(68.8 \%)$

$12(9.8 \%)$

$19(13.5 \%)$

$11.0(10.1)$

10.7 (9.71)

$8.10[2.50,86.9]$

$8.08[2.50,86.9]$

$1.37(0.645)$

1.39 (0.674)

$1.00[0.00,5.00]$

$1.00[0.00,5.00]$

117 (95.9\%)

$134(95.0 \%)$

$5(4.1 \%)$ 


\section{Supplementary Data File S2}

Figure S2a: Overall survival of patients with or without at least one available plasma sample.
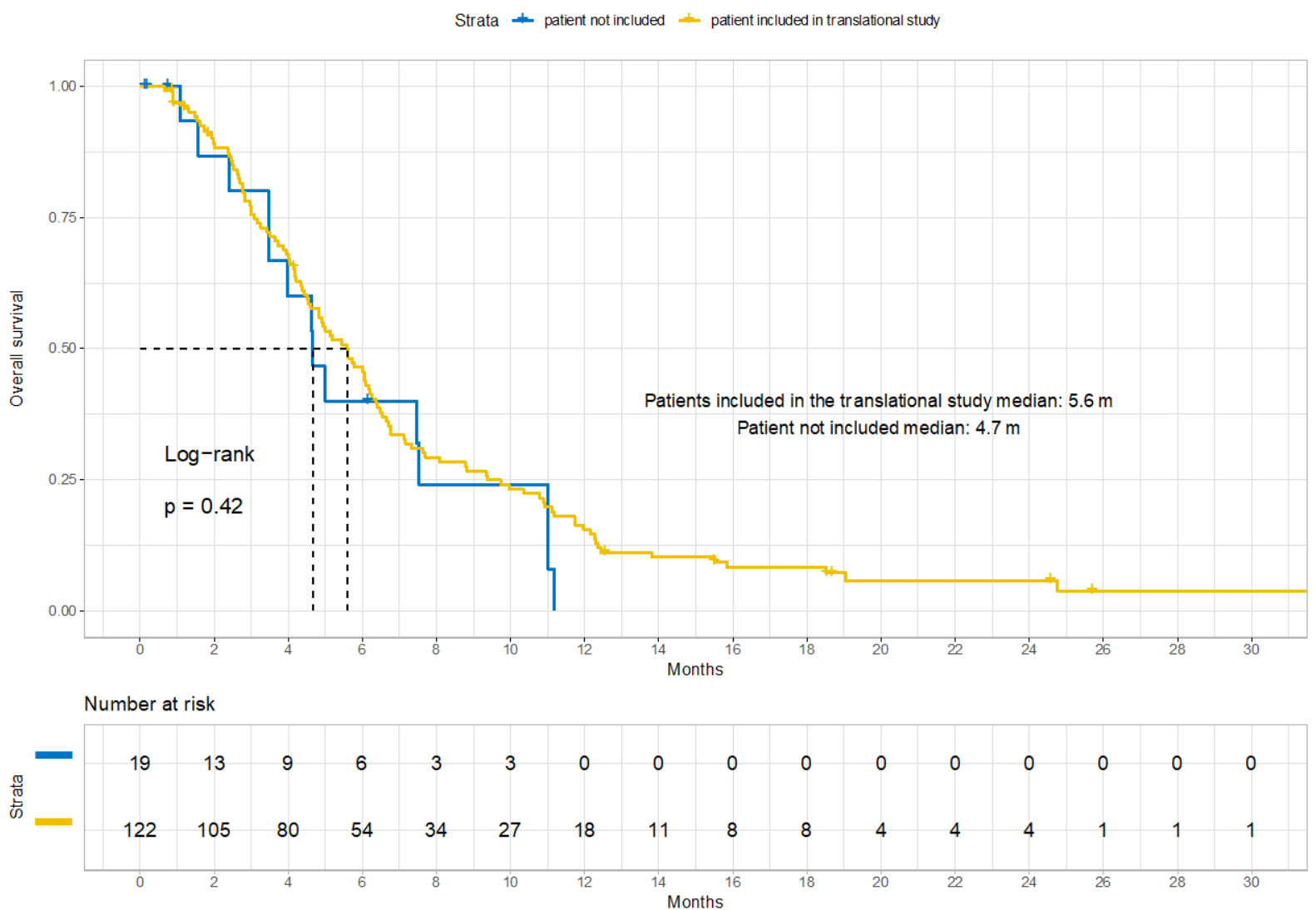

Median overall survivals were of 5.6 and 4.7 months for patients with and without at least one available plasma sample ( $\mathrm{p}=0.52)$, respectively. Median progression free survivals were of 1.8 and 2.1 months for patients with and without at least one available plasma sample $(p=0.61)$, respectively. 
Figure S2b: Overall survival curves according to treatment arms for the 122 patients with at least one available plasma sample.
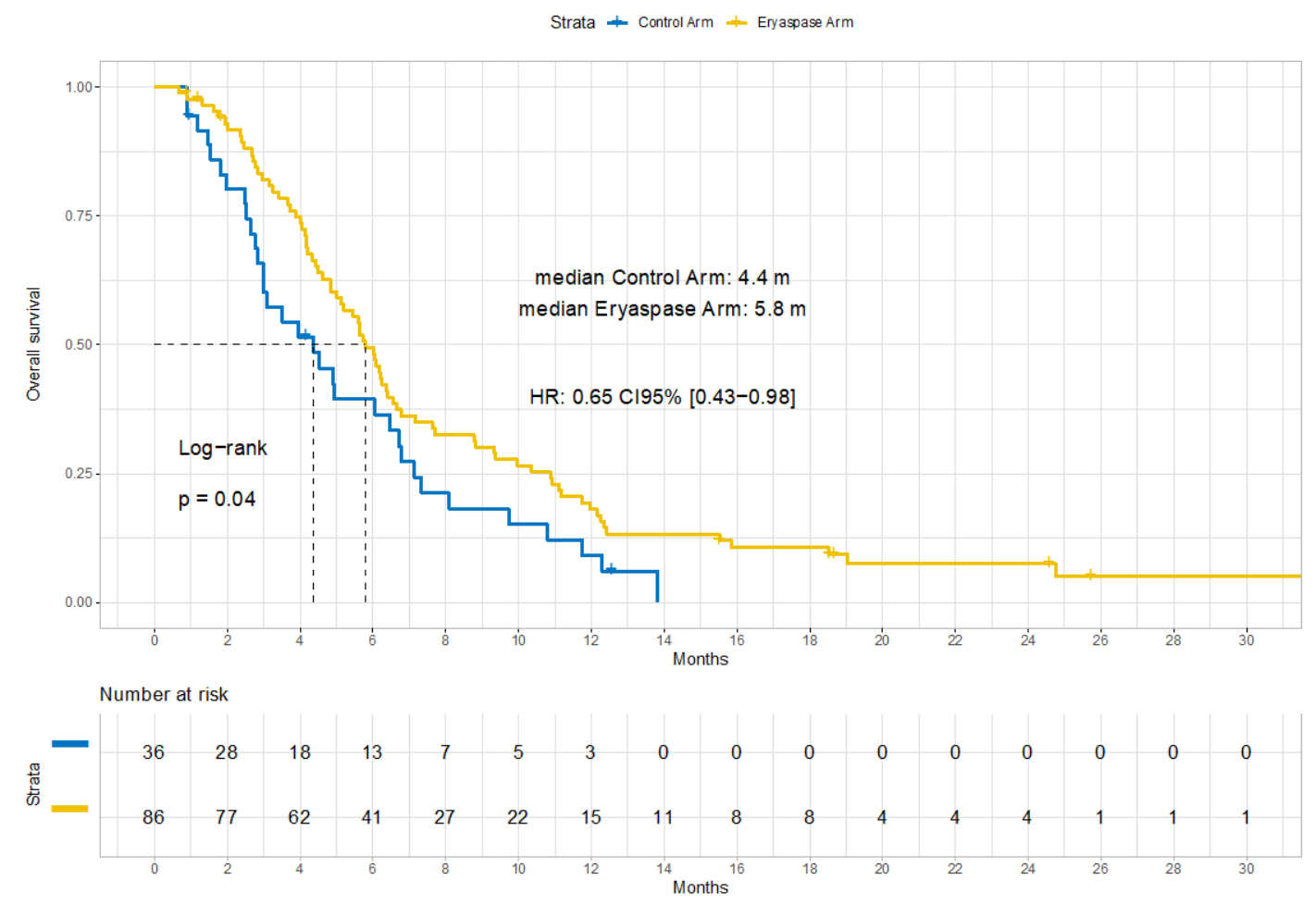

Median overall survivals were of 5.8 and 4.4 months in the eryaspase arm $(n=86)$ and control $\operatorname{arm}(n=36)$, respectively $(\mathrm{HR}=0.65 ; 95 \%$ CI: 0.43-0.98; $\mathrm{p}=0.04)$. 
Figure S2c: Progression free survival curves according to treatment arms for the 122 patients with at least one available plasma sample.
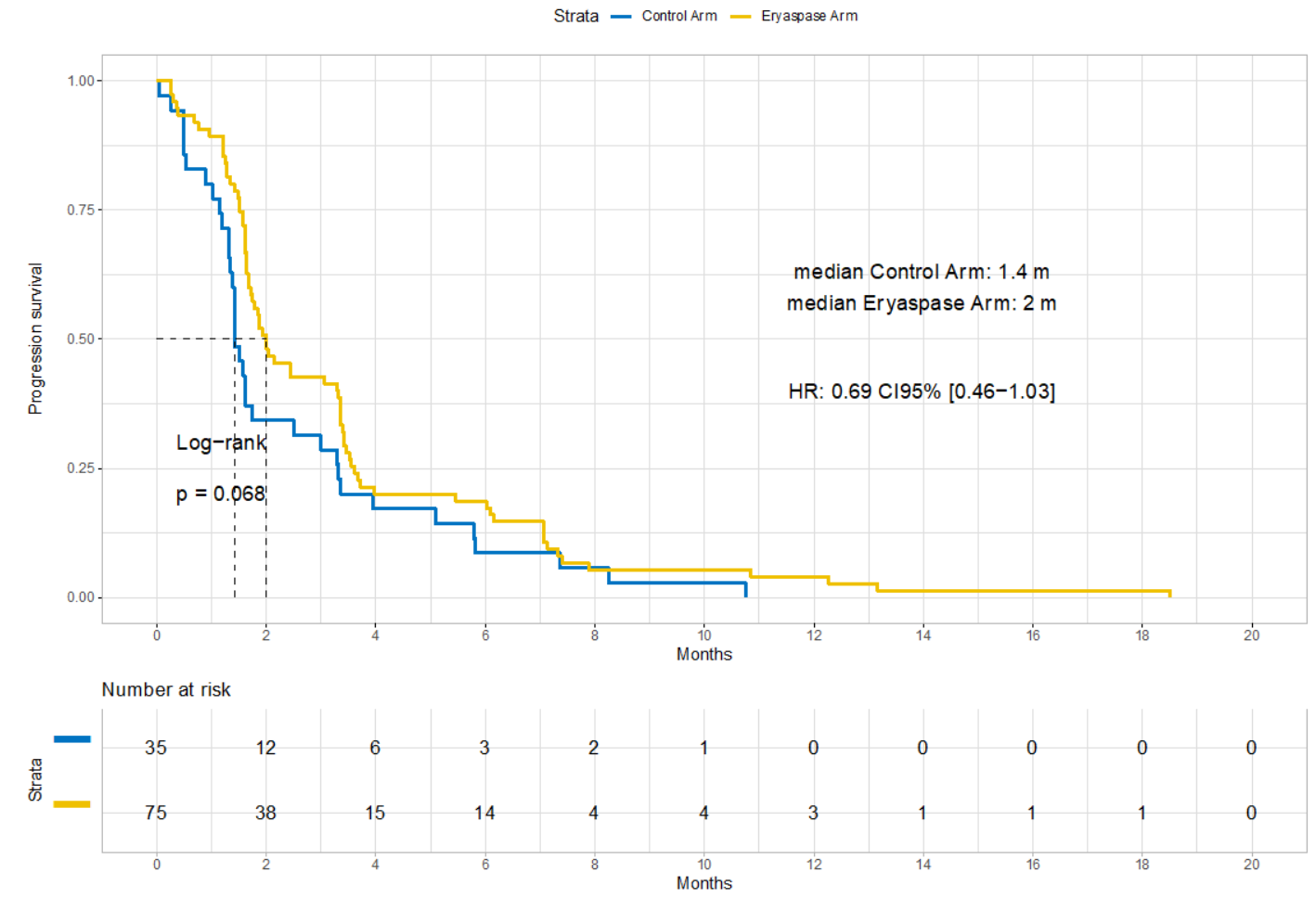

Median progression free survivals were of 2.0 and 1.4 months in the eryaspase arm $(n=75)$ and control arm $(n=35)$, respectively $(\mathrm{HR}=0.69 ; 95 \% \mathrm{CI}: 0.46-1.03 ; \mathrm{p}=0.068)$. 
Supplementary Data File S3: Patients characteristics at baseline according the presence or not of ctDNA

\begin{tabular}{|c|c|c|c|}
\hline & $\begin{array}{c}\text { No detectable } \\
\text { ctDNA } \\
(n=36)\end{array}$ & $\begin{array}{c}\text { Detectable ctDNA } \\
(\mathrm{n}=77)\end{array}$ & $\begin{array}{l}\text { Overall } \\
(n=113)\end{array}$ \\
\hline \multicolumn{4}{|l|}{ Age } \\
\hline Mean (SD) & $61.4(9.70)$ & $62.3(8.93)$ & $62.6(9.72)$ \\
\hline Median [Min, Max] & $62.5[42.0,80.0]$ & $63.0[37.0,84.0]$ & $63.0[37.0,84.0]$ \\
\hline \multicolumn{4}{|l|}{ Gender } \\
\hline $\mathrm{F}$ & $15(41.7 \%)$ & $34(44.2 \%)$ & $58(41.1 \%)$ \\
\hline M & $21(58.3 \%)$ & $43(55.8 \%)$ & $83(58.9 \%)$ \\
\hline \multicolumn{4}{|c|}{ Treatment Arm intend to treat } \\
\hline Control & $8(22.2 \%)$ & $26(33.8 \%)$ & $46(32.6 \%)$ \\
\hline Eryaspase & $28(77.8 \%)$ & $51(66.2 \%)$ & $95(67.4 \%)$ \\
\hline \multicolumn{4}{|c|}{ CA19.9 Normal vs Elevated } \\
\hline Normal & $5(13.9 \%)$ & $14(18.2 \%)$ & $25(17.7 \%)$ \\
\hline Elevated & $26(72.2 \%)$ & $57(74.0 \%)$ & $97(68.8 \%)$ \\
\hline Missing & $5(13.9 \%)$ & $6(7.8 \%)$ & $19(13.5 \%)$ \\
\hline \multicolumn{4}{|c|}{$\begin{array}{l}\text { Time from initial diagnosis to } \\
\text { randomization }\end{array}$} \\
\hline Mean (SD) & $12.9(14.2)$ & $9.96(7.40)$ & $10.7(9.71)$ \\
\hline Median [Min, Max] & $9.92[2.76,86.9]$ & $7.98[2.50,47.9]$ & $8.08[2.50,86.9]$ \\
\hline \multicolumn{4}{|c|}{ Number of metastatic sites } \\
\hline Mean (SD) & $1.44(0.558)$ & $1.38(0.689)$ & $1.39(0.674)$ \\
\hline Median [Min, Max] & $1.00[1.00,3.00]$ & $1.00[1.00,5.00]$ & $1.00[0.00,5.00]$ \\
\hline \multicolumn{4}{|c|}{ Number of metastatic sites } \\
\hline 1 or 2 sites & $35(97.2 \%)$ & $73(94.8 \%)$ & $134(95.0 \%)$ \\
\hline more than 2 sites & $1(2.8 \%)$ & $4(5.2 \%)$ & $7(5.0 \%)$ \\
\hline
\end{tabular}


Supplementary Data File S4: Multivariate analysis of prognostic factors at baseline

\begin{tabular}{|c|c|c|c|c|c|c|}
\hline Factors & estimate & std.error & statistic & p.value & conf.low & conf.high \\
\hline \multicolumn{7}{|l|}{ Overall Survival } \\
\hline $\begin{array}{l}\text { maximal VAF frequency observed at } \\
\text { baseline* }\end{array}$ & 16.80 & 0.75 & 3.74 & 0.00018 & 3.83 & 73.58 \\
\hline Treatment Arm: Eryaspase vs Control & 0.97 & 0.26 & -0.10 & 0.92 & 0.58 & 1.63 \\
\hline Age $^{*}$ & 0.98 & 0.01 & -1.31 & 0.20 & 0.96 & 1.01 \\
\hline Gender: Male vs Female & 0.87 & 0.23 & -0.62 & 0.53 & 0.56 & 1.35 \\
\hline $\begin{array}{l}\text { CA19.9 levels at baseline: Normal vs } \\
\text { Elevated }\end{array}$ & 0.86 & 0.30 & -0.50 & 0.61 & 0.48 & 1.55 \\
\hline Delay before inclusion* & 1.00 & 0.01 & -0.44 & 0.66 & 0.97 & 1.02 \\
\hline Number of metastatic sites* & 0.98 & 0.17 & -0.09 & 0.93 & 0.71 & 1.37 \\
\hline \multicolumn{7}{|l|}{ Progression Free Survival } \\
\hline $\begin{array}{l}\text { maximal VAF frequency observed at } \\
\text { baseline* }\end{array}$ & 5.66 & 0.70 & 2.47 & 0.0135 & 1.43 & 22.39 \\
\hline Treatment Arm: Eryaspase vs Control & 0.87 & 0.25 & -0.57 & 0.56 & 0.53 & 1.42 \\
\hline Age* & 1.00 & 0.01 & -0.37 & 0.71 & 0.97 & 1.02 \\
\hline Gender: Male vs Female & 0.93 & 0.22 & -0.30 & 0.76 & 0.60 & 1.45 \\
\hline $\begin{array}{l}\text { CA19.9 levels at baseline: Normal vs } \\
\text { Elevated* }\end{array}$ & 0.82 & 0.29 & -0.69 & 0.48 & 0.46 & 1.44 \\
\hline Delay before inclusion* & 1.00 & 0.01 & 0.10 & 0.92 & 0.98 & 1.03 \\
\hline Number of metastatic sites* & 1.07 & 0.19 & 0.35 & 0.73 & 0.74 & 1.54 \\
\hline
\end{tabular}

Abbreviation: VAF: variant allelic fraction

* Continuous variables 
Supplementary Data File S5: Description of patients' characteristics according to tertiles of ctDNA VAF frequency at baseline

\begin{tabular}{lccc}
\hline & $\begin{array}{c}\text { 1st tertile } \\
(\mathbf{n}=\mathbf{3 8})\end{array}$ & $\begin{array}{c}\text { 2nd tertile } \\
(\mathbf{n}=\mathbf{3 7})\end{array}$ & $\begin{array}{c}\text { 3rd tertile } \\
(\mathbf{n}=\mathbf{3 8})\end{array}$ \\
\hline Age & & & \\
$\quad$ Mean (SD) & $61.6(9.57)$ & $61.8(9.56)$ & $62.6(8.51)$ \\
$\quad$ Median [Min, Max] & $62.5[42.0,80.0]$ & $64.0[37.0,78.0]$ & $62.5[42.0,84.0]$ \\
Gender & & & \\
$\quad$ Female & $17(44.7 \%)$ & $16(43.2 \%)$ & $16(42.1 \%)$ \\
$\quad$ Male & $21(55.3 \%)$ & $21(56.8 \%)$ & $22(57.9 \%)$ \\
Treatment Arm intent to treat & & & $17(44.7 \%)$ \\
$\quad$ Control & $8(21.1 \%)$ & $9(24.3 \%)$ & $21(55.3 \%)$ \\
$\quad$ Eryaspase & $30(78.9 \%)$ & $28(75.7 \%)$ & $7(18.4 \%)$ \\
CA19.9 Normal vs Elevated & & & $25(65.8 \%)$ \\
$\quad$ Normal & $6(15.8 \%)$ & $6(16.2 \%)$ & $6(15.8 \%)$ \\
$\quad$ Elevated & $27(71.1 \%)$ & $31(83.8 \%)$ & \\
$\quad$ Missing & $5(13.2 \%)$ & $0(0 \%)$ & $2(5.3 \%)$ \\
Time from initial diagnosis to \\
randomization
\end{tabular}


Supplementary Data File S6: Evolution of the maximal variant allelic fraction during the first three cycles in the 40 patients with all three available points.

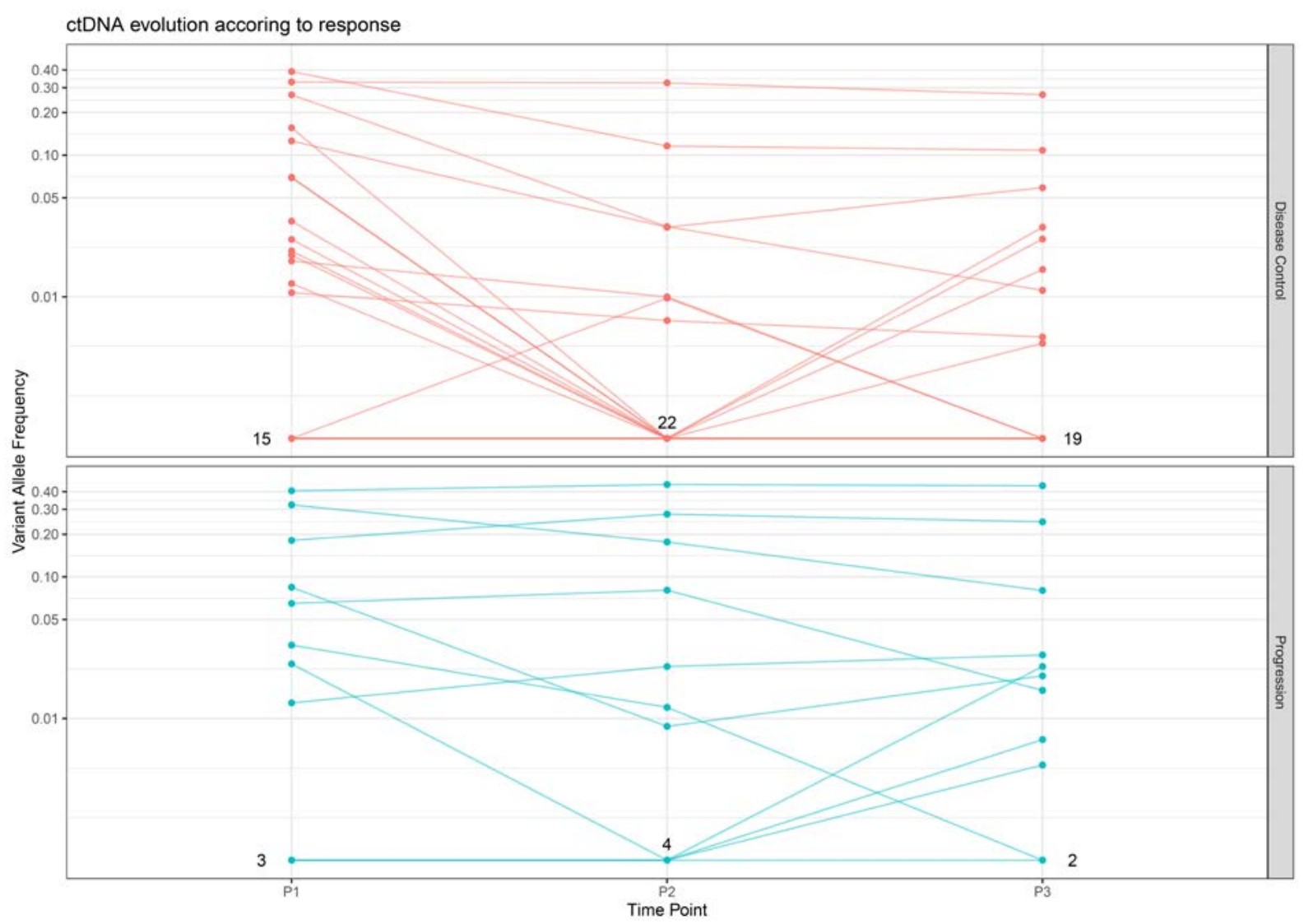

For each graph, the number on the bottom line corresponds to the number of patients with nondetectable (negative) ctDNA at each point. 
Supplementary Data File S7: Interaction between the presence of ctDNA at baseline and eryaspase efficacy on PFS and OS

\begin{tabular}{|c|c|c|c|c|c|c|}
\hline Factors & estimate & std.error & statistic & p.value & conf.low & conf.high \\
\hline \multicolumn{7}{|l|}{ Overall Survival } \\
\hline \multicolumn{7}{|l|}{ Univariate analysis } \\
\hline ctDNA present versus ctDNA absent & 3.94 & 0.47 & 2.94 & 0.00332 & 1.58 & 9.84 \\
\hline Eryaspase arm versus control arm & 1.22 & 0.46 & 0.43 & 0.66377 & 0.50 & 2.98 \\
\hline $\begin{array}{l}\text { ctDNA present:Eryaspase arm } \\
\text { (interaction) }\end{array}$ & 0.39 & 0.52 & -1.79 & 0.07346 & 0.14 & 1.09 \\
\hline \multicolumn{7}{|l|}{ Multivariate analysis } \\
\hline ctDNA present versus ctDNA absent & 4.16 & 0.50 & 2.87 & 0.00415 & 1.57 & 11.01 \\
\hline Eryaspase arm versus control arm & 1.50 & 0.48 & 0.85 & 0.39363 & 0.59 & 3.83 \\
\hline Age & 0.98 & 0.01 & -1.83 & 0.06698 & 0.96 & 1.00 \\
\hline Gender: Male vs Female & 0.75 & 0.22 & -1.30 & 0.19323 & 0.48 & 1.16 \\
\hline $\begin{array}{l}\text { CA19.9 level at baseline Elevated versus } \\
\text { Normal }\end{array}$ & 0.85 & 0.29 & -0.57 & 0.56981 & 0.47 & 1.51 \\
\hline Delay before inclusion & 0.99 & 0.01 & -0.78 & 0.43433 & 0.97 & 1.01 \\
\hline Number of metastatic site & 1.04 & 0.18 & 0.24 & 0.80923 & 0.74 & 1.48 \\
\hline $\begin{array}{l}\text { ctDNA present:Eryaspase arm } \\
\text { (interaction) }\end{array}$ & 0.35 & 0.55 & -1.88 & 0.06012 & 0.12 & 1.05 \\
\hline \multicolumn{7}{|l|}{ Progression Free Survival } \\
\hline \multicolumn{7}{|l|}{ Univariate analysis } \\
\hline ctDNA present versus ctDNA absent & 3.81 & 0.43 & 3.12 & 0.00181 & 1.64 & 8.84 \\
\hline Eryaspase arm versus control arm & 1.12 & 0.41 & 0.27 & 0.78964 & 0.50 & 2.49 \\
\hline $\begin{array}{l}\text { ctDNA present:Eryaspase arm } \\
\text { (interaction) }\end{array}$ & 0.47 & 0.49 & -1.54 & 0.12237 & 0.18 & 1.22 \\
\hline \multicolumn{7}{|l|}{ Multivariate analysis } \\
\hline ctDNA present versus ctDNA absent & 3.93 & 0.47 & 2.92 & 0.00345 & 1.57 & 9.82 \\
\hline Eryaspase arm versus control arm & 1.31 & 0.45 & 0.61 & 0.54264 & 0.55 & 3.15 \\
\hline Age & 0.99 & 0.01 & -0.76 & 0.44972 & 0.96 & 1.02 \\
\hline Gender: Male vs Female & 0.86 & 0.23 & -0.67 & 0.50562 & 0.55 & 1.34 \\
\hline $\begin{array}{l}\text { CA19.9 level at baseline Elevated versus } \\
\text { Normal }\end{array}$ & 0.87 & 0.29 & -0.47 & 0.64139 & 0.49 & 1.55 \\
\hline Delay before inclusion & 1.00 & 0.01 & 0.08 & 0.93554 & 0.97 & 1.03 \\
\hline Number of metastatic site & 1.03 & 0.19 & 0.17 & 0.86501 & 0.72 & 1.49 \\
\hline $\begin{array}{l}\text { ctDNA present:Eryaspase arm } \\
\text { (interaction) }\end{array}$ & 0.42 & 0.53 & -1.62 & 0.10507 & 0.15 & 1.20 \\
\hline
\end{tabular}

